\title{
Laparoscopic resection of large gastric gastrointestinal stromal tumours
}

\author{
Sebastian Smolarek ${ }^{1}$, Eoghan Pomeroy ${ }^{2}$, Fiona Kinnarney ${ }^{3}$, Mayilone Arumugasamy ${ }^{1,2}$ \\ ${ }^{1}$ Connolly Hospital, Royal College of Surgeons in Ireland, Dublin, Ireland \\ ${ }^{2}$ Beaumont Hospital, Royal College of Surgeons in Ireland, Dublin, Ireland \\ ${ }^{3}$ Saint John of God Hospital, Dublin, Ireland
}

Videosurgery Miniinv 2016; 11 (1): 31-37

DOI: 10.5114/wiitm.2015.56489

\begin{abstract}
Introduction: Gastrointestinal stromal tumours (GISTS) are a rare class of neoplasms that are seen most commonly in the stomach. Due to their malignant potential, surgical resection is the recommended method for management of these tumours. Many reports have described the ability to excise small and medium sized GISTs laparoscopically, but laparoscopic resection of GISTs greater than $5 \mathrm{~cm}$ is still a matter of debate.

Aim: To investigate the feasibility and effectiveness of laparoscopic surgical techniques for management of large gastric GISTs greater than $4 \mathrm{~cm}$ and to detail characteristics of this type of tumour.

Material and methods: The study cohort consisted of 11 patients with suspected gastric GISTs who were treated from 2011 to April 2014 in a single institution. All patients underwent laparoscopic resection of a gastric GIST.

Results: Eleven patients underwent laparoscopic resection of a suspected gastric GIST between April 2011 and April 2014. The cohort consisted of 6 males and 5 females. Mean age was 67 years (range: 43-92 years). Sixty-four percent of these patients presented with symptomatic tumours. Four (36.4\%) patients underwent laparoscopic transgastric resection (LTR), 3 (27.3\%) laparoscopic sleeve gastrectomy (LSG), 3 (27.3\%) laparoscopic wedge resection (LWR) and 1 (9\%) laparoscopic distal gastrectomy (LDG). The mean operative time was $215 \mathrm{~min}$. The mean tumour size was $6 \mathrm{~cm}$ (range: 4-9 cm). The mean tumour size for LTR was $5.5 \mathrm{~cm}$ (range: 4-6.3 cm), for LWR $5.3 \mathrm{~cm}$ (range: $4.5-7 \mathrm{~cm}$ ), for LSG $6.5 \mathrm{~cm}$ (range: 4-9 cm) and for LDG $9 \mathrm{~cm}$. We experienced only minor postoperative complications.

Conclusions: Laparoscopic procedures can be successfully performed during management of large gastric GISTs, bigger than $4 \mathrm{~cm}$, and should be considered for all non-metastatic cases. The appropriate approach can be determined by assessing the anatomical location of each tumour.
\end{abstract}

Key words: gastrointestinal stromal tumour, transgastric resection, sleeve gastrectomy, wedge resection.

\section{Introduction}

Gastrointestinal stromal tumours (GIST) are rare tumours of the digestive tract which are mesenchymal in origin. The incidence of GIST is estimated to be between ten and twenty per million [1] per year. They occur most commonly in the stomach
(62-71\%), followed by the small intestine (23-29\%). Other sites such as the oesophagus and the rectum are relatively uncommon $[2,3]$. Gastric GISTs account for approximately $3 \%$ of all gastric tumours and $10-30 \%$ of them behave in an overtly malignant manner. Gastrointestinal stromal tumo are most frequently located in the greater curvature and body of 
the stomach [4]. The malignant potential of GISTs is not easy to predict and depends on many variables such as the size, mitotic activity and location of the tumour within the gastrointestinal tract itself. Overall, it is felt that GISTs originating in the small bowel tend to behave more aggressively than those located in the stomach or oesophagus [5].

The gold standard of treatment for GIST is surgical excision. Furthermore, surgical excision with associated negative resection margins is the recommended treatment for all non-metastatic GISTs [5, 6]. Of note, routine resection of regional lymph nodes during the surgical procedure is not recommended. This is based on the fact that GIST represents a subtype of mesenchymal neoplasm and therefore spreads through direct invasion or haematogenous routes. The actual involvement of lymph nodes is in fact rare, with figures reported to be between $1 \%$ and $4 \%[7,8]$. The use of a surgical technique that promotes careful tissue handling to prevent rupturing of the tumour during resection is absolutely essential. Such unwanted tumour spillage or haemorrhage is directly associated with a high local regional recurrence rate, as well as the actual development of peritoneal sarcomatosis [9]. A recent study that confounds this theory demonstrated that tumour spillage is a negative prognostic indicator of much worse severity than an R1 tumour resection [10].

Laparoscopic approaches are still considered relatively new for GIST surgery. The first report detailing laparoscopic resections of a gastric GIST, along with other benign tumours, was published in 1999 [11, 12]. Since that time laparoscopic techniques have become more popular in the treatment of GIST and are now recommended as the standard procedure for GISTs measuring $<5 \mathrm{~cm}$ [13]. There is still a lot of controversy in relation to laparoscopic resection of GISTs $>5 \mathrm{~cm}$, and the best option for removal of a large gastric GIST has been widely discussed in the literature. However, there is currently no consensus regarding the best approach for managing this tumour laparoscopically.

\section{Aim}

The purpose of this study was to investigate the feasibility and effectiveness of laparoscopic surgical techniques for the management of large gastric GISTs greater than $4 \mathrm{~cm}$ in size and to detail the characteristics of this type of tumour.

\section{Material and methods}

The study cohort consisted of patients with suspected gastric GISTs who were treated from April 2011 to April 2014 in a single institution (Beaumont Hospital, Royal College of Surgery in Ireland, Dublin, Ireland). All patients underwent laparoscopic resection of a GIST. Patient demographics and clinical presentation were analysed. All patients underwent oesophagogastroduodenoscopy (OGD) and a computed tomography scan (CT) prior to the procedure. All the patients were discussed at the Upper Gastrointestinal Multidisciplinary meeting prior to the clinical decision for tumour resection. A formal laparoscopic abdominal exploration was performed to confirm the absence of liver or peritoneal metastasis prior to the surgical resection.

\section{Histological classification}

Histopathological results were analysed for size, presence of negative margins (RO), and mitotic index (number of mitoses per 50 high-power fields). All tumours were analysed for expression of immunohistochemical markers such as: c-kit (CD 117), CD 34, DOG1, desmin, vimentin and smooth muscle myosin. The risk assessment was estimated using the Miettinen classification.

\section{Surgical}

All surgical procedures were performed laparoscopically with the patient placed on a bean bag in the Lloyd-Davis position, with the table tilted to $45^{\circ}$ with the head up. The operating surgeon stood between the patient's legs. A pneumoperitoneum was created using a Veress needle which was inserted into the left upper quadrant. Standard insufflation with carbon dioxide to a pressure of $12-15 \mathrm{~mm} \mathrm{Hg}$ was employed. After establishing the pneumoperitoneum, the camera was introduced using a $12 \mathrm{~mm}$ optical trocar inserted two thirds of the way between the xiphisternum and umbilicus. Three ports were then placed in the abdomen under direct visualization. One $12 \mathrm{~mm}$ port was inserted into the left upper quadrant along the mid-clavicular line and one $5 \mathrm{~mm}$ port was inserted lateral to that. Another $5 \mathrm{~mm}$ port was then inserted into the right upper quadrant along the mid-clavicular line. A $10 \mathrm{~mm} 30^{\circ}$ camera was used in all cases. A Snowden-Pencer articulating liver retractor was used to elevate the left lobe of 
the liver. A $5 \mathrm{~mm}$ laparoscopic LigaSure system was used to divide the gastric vessels. Gastroscopy was performed in the operating room in selected cases to determine the extent of the gastric resection and to further confirm the stapler position prior to resection. The stomach resection was executed using a $12 \mathrm{~mm}$ endo-GA stapler (Covidien, Mansfield MA, USA). Transgastric resection was then performed through an anterior laparoscopic gastrostomy. To avoid tumour spillage, all tumours were placed at an early stage into a laparoscopic retrieval bag, as well as using an Alexis wound protector during the specimen extraction process. After completing the resection, a small incision was made in the left upper quadrant through which to recover the specimen.

In the postoperative phase following a laparoscopic subtotal gastrectomy (LSG), patients were allowed sips of clear fluid on day one, progressing to free fluids on day 2 with an expected advancement to a soft diet on day 3. Patients recovering from alternative surgical resections such as sleeve, wedge or transgastric procedures were allowed to drink clear fluids on day one and were ultimately started on full oral feeding as soon as it was tolerated.

\section{Statistical analysis}

The categorical data are presented as the number of cases and percentages for each group of interest. The continuous data are reported as mean, median and range. Statistical analysis was performed using the StatsDirect version 3.0 for Windows (StatsDirect Ltd. UK). The data was analysed using Mann-Whitney $U$ test.

Table I. Patients demographic

\begin{tabular}{|lc|}
\hline Parameter & Result \\
\hline Gender: & $6(54.5 \%)$ \\
\hline Male & $5(45.5 \%)$ \\
\hline Age at surgery [years]: & $67(43-92)$ \\
\hline Mean (range) & $67 \pm 16$ \\
\hline Median \pm SD & 5 \\
\hline Gastrointestinal bleeding & 4 \\
\hline Incidental findings & 1 \\
\hline Anaemia & 1 \\
\hline Vomiting and weight loss & \\
\hline
\end{tabular}

\section{Results}

Between April 2011 and April 2014, 11 patients underwent laparoscopic resections for suspected gastric GIST. The cohort consisted of 6 (54.5\%) males and 5 females. The mean age was 67 years (range: 43-92 years). Sixty-four percent of the patients presented with symptomatic tumours. The most common symptom was gastrointestinal bleeding followed by chronic anaemia and vomiting with weight loss. Thirty-six percent of the patients were in fact asymptomatic and the mass was an incidental finding during other investigations (Table I).

The majority of tumours were located in the gastric body $(72.7 \%)$, followed by the oesophago-gastric junction (18.2\%) and antrum (9.1\%) (Table II).

None of the patients received neoadjuvant therapy with a tyrosine kinase inhibitor. All procedures were successfully completed laparoscopically. Three (27.3\%) patients underwent gastric laparoscopic wedge resection (LWR), 3 (27.3\%) laparoscopic sleeve gastrectomy (LSG), 4 (36.4\%) laparoscopic transgastric resection (LTR) and 1 (9\%) laparoscopic distal gastrectomy (LDG). The mean operative time was 215 min. The mean operative time for LTR was 220 min (range: 120-345 min), for LWR $231 \mathrm{~min}$ (range: 195-270 $\mathrm{min}$ ), for LDG $195 \mathrm{~min}$ and for LSG 240 min (range: 120-300 min). There was no statistically significant difference between the groups in relation to the operative time $(p=0.894)$. The mean length of stay was 5.6 days (range: 2-16 days). One patient remained in hospital for more than 2 weeks but this was secondary to social reasons only. If these cases are excluded, then the mean length of stay was 4.6 days (range: 2-9 days) (Table III). Overall there were no serious postoperative complications. One patient developed localised port site

Table II. Tumour localization

\begin{tabular}{|lc|}
\hline Variable & Result \\
\hline Oesophago-gastric junction & 2 \\
\hline Stomach body: & 2 \\
\hline Fundus & 2 \\
\hline Lesser curvature & 3 \\
\hline Greater curvature & 1 \\
\hline Posterior gastric wall & 1 \\
\hline Antrum & \\
\hline
\end{tabular}


Table III. Details of surgical procedures and its outcome

\begin{tabular}{|lccccc|}
\hline Procedure & $\begin{array}{c}\text { No. of } \\
\text { patients }\end{array}$ & $\begin{array}{c}\text { Mean tumour } \\
\text { size [cm] }\end{array}$ & $\begin{array}{c}\text { Operative time } \\
\text { and range [min] }\end{array}$ & $\begin{array}{c}\text { Length of stay } \\
\text { and range [days] }\end{array}$ & $\begin{array}{c}\text { Resection } \\
\text { margin }\end{array}$ \\
\hline Laparoscopic transgastric resection (LTR) & 4 & $\begin{array}{c}5.5 \\
\text { (range: 4-6.3) }\end{array}$ & $\begin{array}{c}220 \\
\text { (range: 120-345) }\end{array}$ & $\begin{array}{c}4.5 \\
\text { (range: 4-5) }\end{array}$ & RO \\
\hline Laparoscopic wedge resection (LWR) & 3 & $\begin{array}{c}5.3 \\
\text { (range: 4-7) }\end{array}$ & $\begin{array}{c}231 \\
\text { (range: } 195-270)\end{array}$ & $\begin{array}{c}3.6 \\
\text { (range: 2-5) }\end{array}$ & R0 \\
\hline Laparoscopic sleeve gastrectomy (LSG) & 3 & $\begin{array}{c}6.5 \\
\text { (range: 4-9) }\end{array}$ & $\begin{array}{c}240 \\
\text { (range: } 120-300)\end{array}$ & $\begin{array}{c}8 \\
\text { (range: 4-16) }\end{array}$ & RO \\
\hline Laparoscopic distal gastrectomy (LDG) & 1 & 9.0 & 195 & 9 & $R 0$ \\
\hline
\end{tabular}

bleeding, which was uncovered by a reduction in his haemoglobin and was treated conservatively. There was also one port site hernia, discovered during follow-up in the outpatient department.

Ten $(90.9 \%)$ patients had confirmed GIST according to the final pathological examination. One tumour proved to be a schwannoma. In every case, microscopically assessed resection margins were negative (RO). The mean tumour size was $6 \mathrm{~cm}$ (range: 4-9 cm). The mean tumour size for LTR was $5.5 \mathrm{~cm}$ (range: 4-6.3 cm), for LWR $5.3 \mathrm{~cm}$ (range: 4-7 cm), for LSG $6.5 \mathrm{~cm}$ (range: 4-9 cm) and for LDG $9 \mathrm{~cm}$.

All GISTs were positive for c-kit and CD 34 (100\%), with $70 \%$ positive for DOG-1. The majority of the patients (64\%) had tumour mitotic index value $<5 / 50 \mathrm{HPF}$, and $36 \%$ had no mitotic activity (Table IV). From the metastatic potential point of view, ten tumours belonged to group $3 a$ according to the Miettinen classification (probably benign - very low metastatic potential), regardless of the initial size.

After GIST resection, the need for follow-up was assessed individually for each patient based on the histological classification and age. Surveillance imaging was conducted annually for 2 years. During the follow-up period, one 92-year-old patient, after undergoing a laparoscopic subtotal gastrectomy, developed a distant recurrence (liver) after approximately 12 months. This patient was originally deemed unfit for surgery due to his advanced age and comorbidities. A decision to operate on this patient was made due to a recurrent significant upper gastrointestinal bleed, requiring significant blood transfusions.

Table IV. Histological details of patients GISTs

\begin{tabular}{|lc|}
\hline Mitotic activity & No. of patients \\
\hline No mitotic activity & 3 \\
\hline$<5 / 50$ HPF & 7 \\
\hline
\end{tabular}

\section{Discussion}

Despite the development of targeted molecular therapies such as tyrosine-kinase inhibitors for the management of GISTs, surgical resections remain the cornerstone of treatment for localized disease. The main objective of surgical management is a function-preserving operation with negative margins. Due to the very rare lymphatic spread of GIST, there is no need for routine lymphadenectomy, reserving this procedure only for biopsy-confirmed lymphatic involvement. In our series, $50 \%$ of the patients underwent tumour wedge resections, including transgastric resections. Compared to other available studies we observed higher rates of sleeve gastrectomy. This is mainly due to the large tumour diameter, a situation in which simple wedge resection may lead to stomach distortion and disturbance of function. Sleeve gastrectomy is a safe option for this cohort of patients and, as we reported, there was no significant difference in relation to the operative time, post-operative length of stay or recommencement of oral intake.

The use of a surgical technique that promotes careful tissue handling to prevent tumour rupture is mandatory. Tumour spillage or haemorrhage is associated with high loco-regional recurrence rates as well as the development of peritoneal sarcomatosis [9]. A recent study showed that tumour spillage represents a far worse prognostic factor than R1 tumour resection [10]. In our series we used laparoscopic retrieval bags in the early stages of resection. All exophytic tumour was placed inside the bag to prevent the spillage, prior to laparoscopic dissection. We also use a "non-touch technique", which means that we do not touch the tumour with surgical instruments during the resection.

Where tumours are loco-regionally advanced and not primarily resectable, or where resection would result in poor functional outcome due to tumour 
size, a neoadjuvant therapy with a tyrosine kinase inhibitor (imatinib) may be considered, based on individual evaluation. Clinical studies conducted since 2001 confirm the significant activity of imatinib mesylate in metastatic and inoperable locally advanced GIST. Therefore imatinib should be used as first-line treatment for unresectable and/or metastatic GISTs [5, 6, 14]. Once imatinib therapy has been started, it is recommended to maintain it for 3 to 12 months in order to achieve a maximum response, before proceeding to final radical surgery [15]. In our series none of the patients received neoadjuvant treatment with imatinib.

Traditionally, surgical resection has been achieved by means of open surgery, necessitating prolonged hospital stays and recovery. Laparoscopic approaches are relatively new for GIST surgery. Multiple studies have reported the patient benefits of a laparoscopic approach [16-22]. All these studies reported a significantly lower risk of minor complications associated with laparoscopic surgery, as well as a decreased postoperative hospital stay, shorter time of first flatus, and shorter time for resumption of oral intake. In our series, all patients received enteral feeding from post-operative day one and were discharged at days 3-4 post-operatively, which is sooner than reported in the literature for open surgery.

Total operative time in our study was $215 \mathrm{~min}$, which is longer than reported in other similar studies [19]. The longer operative time probably results from three factors. Firstly, the timings were recorded from the beginning of anaesthesia to patient extubation. Secondly, we used a "non-touch technique" and early protection against the tumour spillage, which significantly increased the technical difficulty and may have contributed to the prolonged operative time. The third factor was the tumour size, which was generally bigger than in other studies. A laparoscopic approach is recommended as a standard procedure for small GISTs $<5 \mathrm{~cm}$ [13]. In our study the mean tumour size was $6 \mathrm{~cm}$, with two tumours of $9 \mathrm{~cm}$. The literature contains a few reports of laparoscopic resections for GISTs bigger than $8 \mathrm{~cm}$, and to date this is a series of laparoscopically resected large gastric GIST including tumours of up to $9 \mathrm{~cm}$. The available studies are listed in Table V.

Table V. Literature review about laparoscopic resection of large gastric GIST

\begin{tabular}{|c|c|c|c|c|c|c|}
\hline Author & $\begin{array}{l}\text { Number } \\
\text { of } \\
\text { patients }\end{array}$ & Year & $\begin{array}{c}\text { Tumor } \\
\text { localization }\end{array}$ & $\begin{array}{c}\text { No. of } \\
\text { conversions to } \\
\text { open procedure }\end{array}$ & $\begin{array}{l}\text { Mean tumour size and } \\
\text { more detail tumour } \\
\text { size characteristic }\end{array}$ & $\begin{array}{l}\text { Recurrence } \\
\text { rate }\end{array}$ \\
\hline $\begin{array}{l}\text { Valle et al. [18], } \\
2013\end{array}$ & 38 & 2004-2012 & $\begin{array}{c}\text { Cardia } 2 \\
\text { Fundus } 10 \\
\text { Lesser curve } 11 \\
\text { Greater curve } 12 \\
\text { Antrum } 3\end{array}$ & 0 & $\begin{array}{c}3.63 \mathrm{~cm} \\
2<2 \mathrm{~cm} \\
26-2-5 \mathrm{~cm} \\
8-5-10 \mathrm{~cm} \\
2>10 \mathrm{~cm}\end{array}$ & Not recorded \\
\hline $\begin{array}{l}\text { Kim et al. [23], } \\
2012\end{array}$ & $\begin{array}{c}104 \\
\text { Lap } 80\end{array}$ & 1998-2011 & $\begin{array}{l}\text { All GIST: } \\
\text { Upper } 61 \\
\text { Middle } 24 \\
\text { Lower } 19 \\
\text { Tumour > } 5 \mathrm{~cm} \text { : } \\
\text { Upper } 19 \\
\text { Middle } 11 \\
\text { Lower } 8\end{array}$ & 0 & $\begin{array}{c}5.1 \pm 3.3 \mathrm{~cm} \\
38 \text { tumours } \\
24 \text { lap cases } \\
\text { Tumour }>5 \mathrm{~cm}\end{array}$ & $\begin{array}{l}4 \text { (1 in lap } \\
\text { group, } 3 \text { in } \\
\text { open group) }\end{array}$ \\
\hline $\begin{array}{l}\text { Karakousis et al. } \\
\text { [24], } 2011\end{array}$ & $\begin{array}{c}155 \\
\text { Lap } 40\end{array}$ & 1998-2009 & Non-GE junction & $\begin{array}{l}13 \text { (5 due to tu- } \\
\text { mour location at } \\
\text { the GE junction } \\
\text { or lesser curve) }\end{array}$ & $\begin{array}{c}\text { All tumours } \\
<8 \mathrm{~cm} \\
\text { Median size } 3.6(0.7-7.8) \\
9 \text { tumours }>5 \mathrm{~cm}\end{array}$ & $\begin{array}{l}1 \text { recurrence } \\
\text { in open and } \\
\text { laparoscopic } \\
\text { group }\end{array}$ \\
\hline $\begin{array}{l}\text { Sokolich et al. [25], } \\
2009\end{array}$ & $\begin{array}{l}4 \text { cases } \\
\text { All lap }\end{array}$ & 2007 & $\begin{array}{l}\text { Body } 3 \\
\text { Antrum } 1\end{array}$ & 0 & $\begin{array}{l}\text { One }-10 \mathrm{~cm} \\
\text { One }-2.5 \mathrm{~cm} \\
\text { One }-3.6 \mathrm{~cm} \\
\text { One }-14 \mathrm{~cm}\end{array}$ & Not recorded \\
\hline $\begin{array}{l}\text { Catena et al. [26], } \\
2008\end{array}$ & $\begin{array}{l}46 \text { cases } \\
\text { Lap } 21 \\
\text { Open } 25\end{array}$ & $2001-2006$ & $\begin{array}{l}\text { Stomach body } 16 \\
\text { Antrum } 4 \\
\text { Fundus } 1\end{array}$ & 0 & $\begin{array}{c}4.5 \mathrm{~cm} \\
(2.0-8 \mathrm{~cm})\end{array}$ & 0 \\
\hline
\end{tabular}


In our study all of the tumours, regardless of the size, were resected with clear margins (RO). There was one recurrence in our study cohort. This occurred in a 92-year-old man, who was originally turned down for operative treatment, but required resection due to recurrent significant upper Gl bleeding. Despite the tumour recurrence, this patient remains alive and is asymptomatic. The results of our study are similar to those obtained by other authors and support the oncological safety of laparoscopic resections.

\section{Conclusions}

Our findings support the application of laparoscopic techniques for the resection of large gastric GISTs. We demonstrated that the clinical outcome is similar to the results obtained from authors resecting GISTs < $5 \mathrm{~cm}$. In situations where larger GISTs are located in the body of the stomach and wedge resections may lead to significant gastric distortions, good alternative options include a sleeve gastrectomy or a laparoscopic distal gastrectomy.

Many current guidelines recommend open resections for large gastric GISTs $>5 \mathrm{~cm}$, due to their theoretical malignant potential. In our series, none of the resected tumours were classified in the high malignant potential groups after careful histological examinations. The risk of spillage can be very easily eliminated by the "non-touch technique", early use of retrieval bags and wound protectors. In these situations the size should then not be taken into account as a cut-off point for laparoscopic resections.

To allow for definitive recommendations of laparoscopic surgery as a new standard for large gastric GISTs, it would be necessary to have results from at least one randomised control trial. It would be extremely difficult to design this study, due to the rarity of large gastric GISTs. In our opinion, based only on our experience and available retrospective data, we believe that laparoscopic resection of a large gastric GIST is a safe procedure from a surgical and oncological point of view, and offers comparable results to open surgery with lower postoperative morbidities. However, we strongly recommend that this procedure be carried out in specialist upper Gl centres, with high levels of laparoscopic experience. We also recommend that every case should be carefully discussed at specialised upper GI multidisciplinary meetings, prior to surgery.

\section{Conflict of interest}

The authors declare no conflict of interest.

\section{References}

1. Goettsh WG, Bos SD, Breekveldt-Postma N, et al. Incidence of gastrointestinal stromal tumors is underestimated: results of nation-wide study. Eur J Cancer 2005; 41: 2868-72.

2. Raventos VA, Pousa AL, Medina LO, et al. Primary, non-metastatic gastrointestinal stromal tumor surgery: result of the GRISK Study. Cir Esp 2013; 91: 96-102.

3. Mucciarini C, Rossi G, Bertolini F, et al. Incidence and clinicopathologic features of gastrointestinal stromal tumors. A population-based study. BMC Cancer 2007; 20: 230.

4. Fletcher CD, Berman JJ, Corless C, et al. Diagnosis of gastrointestinal stromal tumors: a consensus approach. Hum Pathol 2002; 33: 459-65.

5. The ESMO/European Sarcoma Network Working Group. Gastrointestinal stromal tumors: ESMO Clinical Practice Guidelines for diagnosis, treatment and follow-up. Ann Oncol 2012; 23 (Suppl. 7): 49-55.

6. Poveda A, Rivera F, Martín J. Spanish Group for Sarcoma Research (GEIS). SEOM guidelines for gastrointestinal stromal sarcomas (GIST). Clin Transl Oncol 2012; 14: 536-40.

7. Agaimy A, Wunsch PH. Lymph node metastasis in gastrointestinal stromal tumours (GIST) occurs preferentially in young patients $\leq 40$ years: an overview based on our case material and the literature. Langenbecks Arch Surg 2009; 394: 375-81.

8. De Matteo RP, Lewis JJ, Leung D, et al. Two hundred gastrointestinal stromal tumors. Recurrence patterns and prognostic factors for survival. Ann Surg 2000; 231: 51-8.

9. Gold JS, Dematteo RP. Combined surgical and molecular therapy: the gastrointestinal stromal tumor model. Ann Surg 2006; 244: 176-84

10. McCarter MD, Antonescu CR, Ballman KV, et al.; American College of Surgeons Oncology Gropu (ACOSOG), Intergroup Adjuvant GIST Study Team. Microscopically positive margins for primary gastrointestinal stromal tumors: analysis of risk factors and tumor recurrence. J Am Coll Surg 2012; 215: 53-9.

11. Barlehner E. Initial experience with laparoscopic gastrectomy in benign and malignant tumors. Zentralbl Chir 1999; 124: 346-50.

12. Chenge HL, Lee WJ, Lai IR, et al. Laparoscopic wedge resection of benign gastric tumor. Hepatogastroenterology 1999; 46: 2100-4.

13. Nishida T, Hirota S, Yangisawa A, et al. Clinical practice guidelines for gastrointestinal stromal tumor (GIST) in Japan: English version. Int J Clin Oncol 2008; 13: 416-30.

14. Bareck E, Ba-Ssalamah A, Brodowicz T, et al. Gastrointestinal stromal tumors: diagnosis, therapy and follow-up care in Austria. Wien Med Wochenschr 2013; 163: 137-52.

15. Poveda A, Rivera F, Martin J. Spanish Group for Sarcoma Research (GEIS). SEOM guidelines for gastrointestinal stromal sarcomas (GIST). Clin Transl Oncol 2012; 14: 536-40.

16. De Vogelaere K, Hoorens A, Haentjens P, Delvaux G. Laparoscopic versus open resection of gastrointestinal stromal tumors of the stomach. Surg Endosc 2013; 27: 1546-54. 
17. Pucci MJ, Berger AC, Lim PW, et al. Laparoscopic approaches to gastric gastrointestinal stromal tumors: an institutional review of 57 cases. Surg Endosc 2012; 26: 3509-14.

18. Valle M, Federici O, Carboni F, et al. Gastrointestinal stromal tumors of the stomach: the role of laparoscopic resection. Single-centre experience of 28 cases. Surg Endosc 2014; 28: 1040-7.

19. De Vogelaere K, Van Loo I, Peters O, et al. Laparoscopic resection of gastric gastrointestinal stromal tumors (GIST) is safe and effective, irrespective of tumor size. Surg Endosc 2012; 26: 2339-45.

20. Jeong IH, Kim JH, Lee SR, et al. Minimally invasive treatment of gastric gastrointestinal stromal tumors: laparoscopic and endoscopic approach. Surg Laparosc Endosc Percutan Tech 2012; 22: 244-50.

21. Melstorm LG, Phillips JD, Bentrem DJ, Wayne JD. Laparoscopic versus open resection of gastric gastrointestinal stromal tumors. Am J Clin Oncol 2012; 35: 451-4.

22. Wan P, Yan C, Li C, et al. Choices of surgical approaches for gastrointestinal stromal tumors of the stomach: laparoscopic versus open resection. Dig Surg 2012; 29: 243-50.

23. Kim KH, Jung GJ, Kim SJ, et al. Long term survival result for gastric GIST: is a laparoscopic surgery for large gastric GIST feasible? World I Surg Oncol 2012; 10: 230.

24. Karakousis GC, Singer S, Zheng J, et al. Laparoscopic versus open gastric resections for primary gastrointestinal stromal tumors (GISTs): a size-matched comparison. Ann Surg Oncol 2011; 18: 1599-605.

25. Sokolich J, Galanopoulos C, Dunn E, et al. Expanding the indications for laparoscopic gastric resection for gastrointestinal stromal tumors. JSLS 2009; 13: 165-9.

26. Cantena F, Di Battista M, Fusaroli P, et al. Laparoscopic treatment of gastric GIST: report of 21 cases and literature's review. J Gastrointest Surg 2008; 12: 561-8.

Received: 30.09.2015, accepted: 17.11.2015. 